Teoria e prática

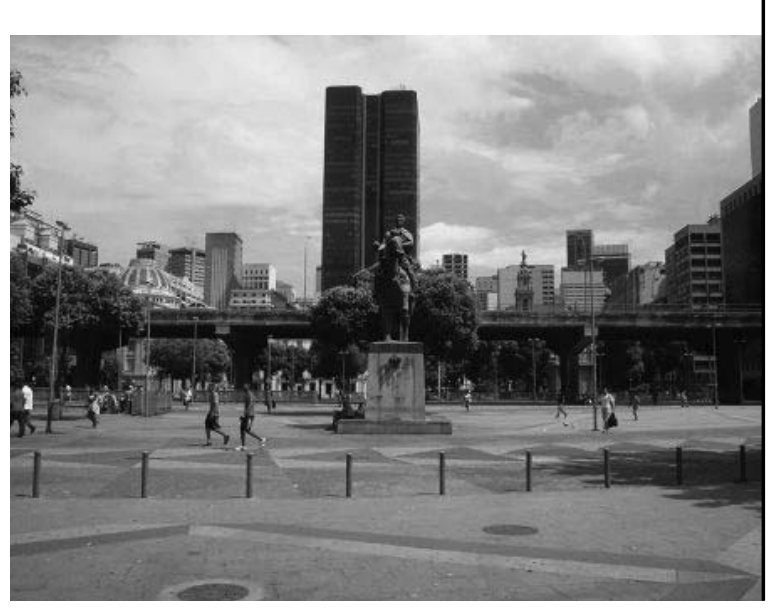





\title{
Prácticas y usos del espacio marino a través del tiempo en caletas de pescadores artesanales: El Manzano y Puntilla Pichicolo, Comuna de Hualaihué, Provincia de Palena, Chile*
}

Práticas e usos do espaço marinho ao longo do tempo em bairros de pescadores artesanais: El Manzano e Puntilla Pichicolo, município de Hualaihué, Província de Palena, Chile

\section{Practices and uses of marine space over time in two artisanal fisheries communities: the case of El Manzano and Puntilla Pichicolo located in Hualaihué of Palena Province, Chile}

Pratiques et modes d'utilisation de l'espace marin dans des quartiers de pécheurs artesanales: El Manzano et Puntilla Pichicolo, ville de Hualaihué, province de Palena, Chile

\author{
Paula Salinas Vilches** \\ Francisco Ther Ríos***
}

Recebido em 10/03/2010; revisado e aprovado em 19/06/2010; aceito em 19/05/2011

\begin{abstract}
Resumen: Se presenta una caracterización de las prácticas y usos del espacio marino, destacando la influencia que ha tenido la Legislación Pesquera (Ley n.18.892) en la modificación de las formas tradicionales de producción pesquero-artesanal para lo cual se presentan los casos de dos caletas de pescadores artesanales en la Comuna de Hualaihué, sur de Chile. En estos asentamientos se han introducido nuevas figuras de administración pesqueras que se materializan en nuevos usos del espacio. Lo anterior, sirve como marco para exponer las formas territoriales utilizadas en el tiempo por pescadores artesanales para responder a la menor biodisponibilidad de recursos, lo cual se relaciona a su vez con con las modificaciones en las artes extractivas tradicionales.

Palabras clave: Pesca artesanal. Saberes pesqueros tradicionales. Legislación pesquera.

Resumo: Apresenta-se uma caracterização de práticas e usos do espaço marinho, destacando a influência exercida pela legislação pesqueira (Lei no.18.892) sobre a modificação das formas tradicionais de produção pesqueiroartesanais. Para isso apresentam-se os casos de dois bairros de pescadores artesanais do Município de Hualaihué, sul do Chile. Nestas colônias foram introduzidas novas figuras de administração pesqueira que se materializam em novos usos do espaço. $\mathrm{O}$ anterior torna-se um marco para expor as formas territoriais usadas ao longo do tempo pelos pescadores artesanais para responder à diminuição da biodisponibilidade dos recursos, o que, por sua vez, tem relação com as modificações nas artes extrativistas tradicionais.

Palavras-chave: Pesca artesanal. Saberes pesqueiros tradicionais. Legislação pesqueira.

Abstract: A characterization of the practices and uses of marine space, highlighting the influence it has had the Fisheries Law (Law n. 18.892) in the modification of the traditional modes of life about artisanal fisheries, which are the cases of two artisanal fishing organizations located in Hualaihué, southern Chile. In these settlements have been introduced new fisheries management figures that materializing into new uses of space. This serves as a framework to expose the territorial forms used by artisanal fishermen time to respond to the lower bioavailability of resources, which in turn is associated with changes in the traditional gear to extracting.

Key words: Artisanal fishing. Traditional fisheries knowledge. Fisheries legislation.

Résumé: Letexte donne une caractérisation des pratiques et des usages del'espace marin, en soulignant l'influence de la législation sur lapêche (loi n.18.892), sur la modification des formestraditionnelles de la pêche artisanale de production. Pour ceci, ilest présenté le cas de deux quartiers de la ville de pêcheursHualaihué, sud du Chili. Dans ces colonies ont été introduites desnouvelles figures de gestion de la pêche qui se matérialisent en denouveaux usages de l'espace. Ce qui a été décrit sert alors decadre pour exposer les formes territoriales employées dans le tempspar les pêcheurs artisans, en essayant de répondre à la diminutionde la biodisponibilité des ressources, ce qui, à son tour, a uneliaison avec les changements dans les domaines traditionnelsd'extraction.

Mots-clés: PêcheArtisanale. Savoirs sur la Pêche Traditionnelle. Législation sur laPêche.
\end{abstract}

\footnotetext{
* Este trabajo es resultado del Proyecto FONDECYT 1080665 “Las sociedades litorales como sistemas de prácticas y saberes tradicionales y científicos: la caleta como modelo de imaginarios pesqueros y dinámicas de uso y apropiación de recursos marinos".

** Geógrafo. Estudiante Tesista Magister en Ciencias Sociales, Centro de Estudios del Desarrollo Local y Regional. Universidad de Los Lagos. E-mail: geo.psalinas@gmail.com .

*** Antropólogo. Docente-investigador, Centro de Estudios del Desarrollo Local y Regional / Universidad de Los Lagos. Dirección Postal: Calle Lord Cochrane 1056, Osorno, Región de Los Lagos, Chile. E-mail: fther@ulagos.cl.
} 
Ante el problema de la sobreexplotación de recursos marinos la tendencia mundial ha sido buscar nuevas alternativas de manejo y conservación, uno de estos métodos ha sido la acuicultura, que ha llegado a ser el mayor abastecedor de pescados y mariscos de los mercados alrededor del mundo, una situación que probablemente persistirá en el futuro; por una parte, la captura de pesca libre a nivel mundial apremia y amenaza los límites de la producción renovable, y, por otra, el consumo global de pescado se ha doblado desde principios de 1970 (NAYLOR; BURKE, 2005), y continuará creciendo conforme siga el aumento de la población en el mundo. La demanda de pescado no sólo está ascendiendo sino que las nuevas exigencia de los consumidores obligan a modificar los antiguos estándares de calidad de los productos (NAYLOR; BURKE, 2005), de esta manera lo tradicional (local) se vuelve ineficiente para satisfacer las necesidades que impone la sociedad demandante (CANCLINI en MARÍN, 2007).

Las regulaciones legales de la pesca artesanal han impuesto nuevas formas de manejo tanto de los recursos como del uso de los espacios marinos; a este respecto Gualarte e Girondi (2008) plantean como el manejo convencional (tradicional) pesquero está basado exclusivamente en métodos e informaciones científicas, ignorando el conocimiento y manejo que informalmente ha sido adquirido por las comunidades de pescadores. Como consecuencia de esto se tiene que la implementación de las bases convencionales del manejo de los sistemas es usualmente complicado, caro e inoperante, no tomando parte ni los pescadores ni otros actores locales parte en los procesos de toma de decisiones, incumpliéndose con ello incluso las mismas normativas. Marín (2007) señala que este nuevo sistema de modernización introduce nuevas complejidades, lo cual provoca cambios en todos los ámbitos de la vida social y cultural, pasando de una cultura extractiva a un modo de producción regulado, que promueve la lógica de la asociatividad eliminando el individualismo en las faenas alterando sus prácticas.

Los cambios que la legislación pesquera chilena ha tenido durante las dos últimas décadas ha traído conflictos entre lo tradicional y lo moderno, lo que se expresa entre otros en el ordenamiento del espacio marino no sólo en función de la distribución y localización de los recursos marinos, sino - y por sobre todo - en un marco legislativo que somete la actividad a una definición de tipo funcional estática, regionalmente delimitada para los pescadores que se dedican a la explotación de recursos demersales ${ }^{1}$, quitándole el dinamismo por el cual eran conocidos quienes extraían estos recursos e introduciendo el concepto de límites y perímetros de acción (Ley General de Pesca y Acuicultura) por medio de figuras de administración pesquera que para el caso de los recursos bentónicos declara áreas específicas para la administración y manejo de especies en estado natural (Áreas de Manejo y Explotación de Recursos Bentónicos, AMERB) y la producción de recursos hidrobiológicos organizados por el hombre (Concesiones Acuícolas).

Estos procesos han desencadenado transformaciones sociales y cambios en los códigos de comportamiento local, así como también en el sistema de valores de la comunidad local, lo que finalmente ha ocasionado un cambio en los tipos de organización social, en sus relaciones dentro de la comunidad y con otros miembros de comunidades vecinas (BARRAGÁN en BERAÚN, 2007). Estas transformaciones tienen una expresión territorial, y se manifiestan en los usos del espacio marino que se exhiben en todos los niveles de la organización espacial; resultante del proceso de cambios en los aspectos de la vida y la conducta social, en el que surgen nuevas estructuras físicas, y se modifican las antiguas con la aparición de nuevos niveles y formas de organización territorial (WEITZ en BERAÚN, 2007). De este modo el territorio se va construyendo como el reflejo de acciones y comportamientos múltiples acumulados en el tiempo, con capacidad de influir de forma significativa en su estructura y funcionamiento (MÉNDEZ, 2006). Los territorios, por lo tanto, dejan de ser una simple proyección espacial de las estrategias y políticas nacionales de pesca, para caracterizarse en la actualidad más bien por la glocalidad con los encuentros y desencuentros entre procesos y acciones que realizan grupos socioeconómicos (GUDIÑO, 2005), los grupos locales y el poder político. En

\footnotetext{
${ }^{1}$ Además de un sistema de cuota de extracción para la Merluza del Sur (Merluccius australis).
} 
este escenario las imbricaciones son variadas; los fenómenos globalizadores, por ejemplo, ejercen gran influencia en los usos del espacio marino local, modificando las antiguas estructuras espaciales que pueden ser observadas como "trayectorias específicas de adaptación de las sociedades a los espacios supranacionales de la globalización" (KLEIN, 2006, p. 307). Esta adaptación se traduce en nuevas formas de organización del espacio marino y sus recursos, que no implica

[...] la simple sucesión de una forma económica por otra, sino a la superposición y combinación de formas de organización social y estructuras industriales, volviendo más complejo el análisis de los territorios. (ROSALES, 2006, p. 136).

Beraún (2007) sostiene que la sobrevivencia de las poblaciones con estructura productiva tradicional responde a objetivos supranacionales generando cambios a escala local en los tipos de organización social y en las formas de organización territorial, en este caso las estrategias de desarrollo económico (Estrategia de Desarrollo Regional - Los Lagos, 2000-2010) ejercen una fuerte presión sobre aquellos territorios caracterizados por la riqueza en recursos marinos. Por consiguiente, los espacios litorales se van constituyendo como espacios estructurales $\mathrm{y}$, a la vez, estructuradores tanto del territorio como de las prácticas que se desarrollan en él.

En este estudio se realizó una caracterización de la economía de las caletas y la espacialización cartográfica de los usos pesquero artesanales que se han realizado a través del tiempo, con objeto de analizar las dinámicas territoriales litorales de las caletas, describiéndose la influencia de la Ley General de Pesca en la transformación, adaptación y hasta el abandono de las prácticas pesqueras tradicionales y usos de los espacios litorales; interesa responder a las siguientes cuestiones: ¿qué eventos han generado cambios en los usos del espacio marino en las caletas? y ¿cómo estos eventos han afectado las prácticas pesquero artesanales de las caletas?

\section{Área de estudio}

Como unidad territorial de análisis se eligieron dos caletas de pesca artesanal: Puntilla Pichicolo y El Manzano, ambas son consideradas como unidades productivas, económicas y sociales sobre las cuales se ha focalizado la acción del Estado chileno. Estas caletas se encuentran en el sector norte de la comuna de Hualaihué, en la Provincia de Palena, Región de Los Lagos, en el mar interior de Chiloé (Cartografía n.1). Las caletas dependen de los servicios que presta Hornopirén, la capital comunal; bancos, registro civil, correo, mercado, supermercado entre otras. En ambas caletas las escuelas solamente completan la educación básica para continuar los estudios de la enseñanza media las localidades más cercanas son: Contao, Hornopirén y Puerto Montt. 


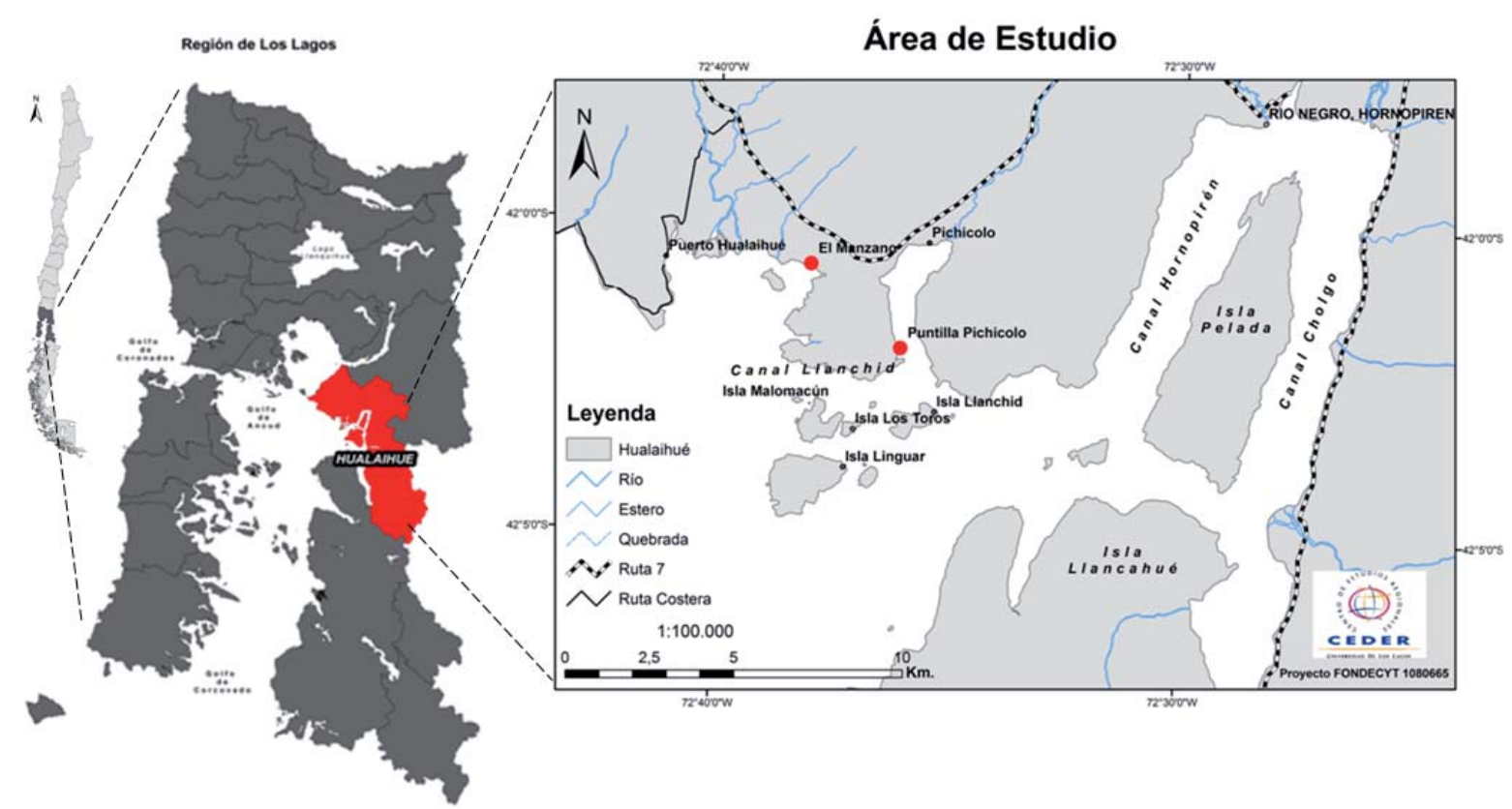

Cartografía n. 1 - Área de Estudio

Fuente: Elaboración Propia

La Caleta El Manzano tiene una población de 358 personas según el último Censo del 2002, posee luz eléctrica pero no agua potable ya que se abastecen de agua sacada desde un pozo profundo para un total de 40 familias, tampoco existe sistema alcantarillado, por lo que cada familia ha diseñado su propio sistema de eliminación de excretas (FUNDACIÓN CHINQUIHUE, 2008). El Manzano se caracteriza por presentar amplias zona de intermareal, abarcando entre bajamar y pleamar una distancia de entre 1 a 1,5 kilómetros de longitud, esta amplitud mareal favorece la recolección de mariscos, cuyas principales especies son las Navajuelas (Tagelus dombeii), Almejas (Venus antiqua), Choritos (Mytilus chilensis) y Cholgas (Aulacomya Ater) (FUNDACIÓN CHINQUIHUE, 2008).

Cerca del $65 \%$ de la población económicamente activa se desenvuelve en actividades asociadas a la explotación de recursos marinos, actividad que es desarrollada tanto por hombres como por mujeres, representando la principal fuente de ingresos familiares combinando las pesquerías demersales, la recolección de mariscos de orilla, el buceo y la acuicultura. La actividad se encuentra organizada por medio de tres Sindicatos de Pesca Artesanal. En tanto la agricultura sólo se realiza dentro del marco del autoconsumo (FUNDACIÓN CHINQUIHUE, 2008).
El año 2005 fueron ingresadas las primeras solicitudes de AMERB para la Caleta, a través de los Sindicatos El Manzano y San Pedro. La AMERB que hoy tiene el Sindicato el Manzano tiene una superficie total de 160 hectáreas, mientras que la AMERB del Sindicato San Pedro tiene 300,5 hectáreas ${ }^{2}$.

Por su parte, la Caleta Puntilla Pichicolo se encuentra frente a Caleta Pichicolo Puerto, según los registros manejados desde el Gobierno Regional de la Región de Los Lagos, la localidad no es reconocida como Caleta de pescadores, ya que no se encuentra decretada. Hasta hace algún tiempo Puntilla Pichicolo no poseía conexión vía terrestre con otras localidades ni entre vecinos por lo cual sólo se movilizaban en embarcaciones de tamaño menor, aun en la actualidad quedan los vestigios de esta época teniendo cada vivienda un pequeño muelle para anclar su embarcación.

Puntilla Pichicolo tiene 158 habitantes, no cuenta con luz eléctrica, se abastecen de esta por medio de un generador de corriente que funciona con petróleo durante las 19 y 23 horas (en invierno), variando este horario según la estacionalidad. En el lugar no llega señal de teléfonos móviles, siendo el sistema de radio el único medio de telecomunicación.

\footnotetext{
${ }^{2}$ En el momento en que se recolectó la información no existían registros de Concesiones Acuícolas en la Caleta.
} 
En cuanto a equipamiento, el desembarque se realiza en la caleta Pichicolo, ya que la caleta no cuenta con rampa de desembarque. Los pescadores de caleta Puntilla Pichicolo, se dedican básicamente a la extracción de merluza del Sur en el mar interior de Chiloé durante todo el año, exceptuando el mes de agosto en que existe veda del recurso. La actividad pesquero artesanal está organizada a través de los sindicatos de pesca. Existen tres Sindicatos en la caleta.

En el año 2005 fue ingresada la primera solicitud de AMERB llamada Puntilla Pichicolo de 35,2 hectáreas de extensión, le siguió Este Puntilla Pichicolo de 37,5 hectáreas en el año 2007. En tanto la Concesión Acuícola más antigua registrada para este sector se dedica a la salmonicultura y corresponde a la empresa LEFERSA Alimentos S.A. la cual comenzó a funcionar a finales de 1999 con 24,54 hectáreas de extensión. En el año 2001 fue otorgada la primera Concesión de Mitilicultura (21 há.). El resto de la concesiones son de propiedad de particulares que solicitaron la administración de las columnas de agua para la captación de semillas de mitílidos, tanto dentro del Estero Pichicolo, como en el sector del Canal Llanchid. La última concesión registrada cartográficamente en el Gobierno Regional corresponde al año 2003, por tanto, se puede observar que la ocupación actual del espacio marino difiere considerablemente de lo representado en la cartografía (Cartografía n. 5).

\section{Antecedentes de la Política y Legislación Pesquero-Artesanal}

Pese a que la Ley de General de Pesca y Acuicultura fue publicada el año 1991, la Política de Administración Pesquera comenzó a aplicarse recién el año 2007, este hecho explica en gran medida el descontrol que ha tenido la actividad que constantemente amenaza con desaparecer los recursos hidrobiológicos, un ejemplo de esto es lo que ha ocurrido con la sobreexplotación del recurso loco (Concholepas concholepas) que paso de explotar 67 toneladas en 1926 a 24 mil 856 toneladas para 1980 (REYES, 1986). La Política de Administración Pesquera brinda una

[...] guía de lineamiento estratégico explícito, de largo plazo y de mayor coherencia con el resto de las políticas gubernamentales, sobre el quehacer de esta actividad productiva de tanta relevancia para nuestro país. (SUBPESCA, 2007).

con el fin de

[...] promover el desarrollo sustentable del sector pesquero, procurando el crecimiento económico, con mecanismos de gobernabilidad y en un marco de equidad, para el bienestar de todos. (SUBPESCA, 2007).

Por su parte, la Ley General de Pesca u Acuicultura establece Figuras de Administración Pesqueras entre las cuales se encuentran las Áreas de Manejo y Explotación de Recursos Bentónicos (AMERB) y las Concesiones Acuícolas. Existe una diferencia fundamental en el funcionamiento y manejo de cada una de estas figuras de administración pesqueras; mientras la primera es de derecho exclusivo de las organizaciones de pescadores artesanales (Sindicatos y Cooperativas), la segunda permite que particulares puedan optar a ellas, lo que genera una gran brecha en cuanto a la celeridad con que los segundos pueden gestionar los trámites administrativos de solicitud de las concesiones que suelen ser bastante lentos.

En la Política Nacional Pesquera se pueden reconocer al menos dos periodos de la actividad. En el Primer periodo (1989-2001) se publica la Ley de Pesca y Acuicultura del año 1991, con esto se logra crear un Registro de Pescadores Artesanales (RPA), formalizando la actividad por medio de la regionalización del pescador obligándolo a trabajar sólo en la región en la cual se encuentra inscrito, de este modo la explotación de recursos se vuelve exclusiva para quienes se encuentren registrados en la región, además se

[...] consignaron áreas preferentes de uso para este sector y concedieron facultades de administración especificas para áreas de reserva artesanal. Es también en este período que nace el régimen de áreas de manejo y explotación de recursos bentónicos. (SUBPESCA, 2007).

El Segundo periodo parte en el año 2001 con la Ley n. 19.713 en la cual se establece el

[...] límite máximo de captura por armador que es una nueva medida de administración que asigna cuotas de captura (límite máximo) entre los armadores que cuentan con autorizaciones de pesca vigentes en una pesquería determinada. (SUBPESCA, 2007). 
La Política de Administración Pesquera relata la evolución de la pesca durante la década de los ochenta mientras regía el régimen de libre acceso a los recursos pesqueros y la posterior fijación de cuotas globales de captura, estas etapas trajeron como consecuencia la reducción de los stocks de estos recursos, además de la disipación de la renta de los pescadores artesanales ya que comenzaron a competir con flotas industriales que tienen una mayor capacidad para extraer grandes volúmenes de recursos, sin importar los costos involucrados (SUBPESCA, 2007).

En 1994 se implementó un sistema de cuota de extracción tanto para la pesca industrial como artesanal, debido a que el desembarque y la captura (especialmente del recurso merluza) seguían aumentando al igual como ocurría en los ochentas, pues se llevaba un ritmo descontrolado de explotación, esto "amenazaba con agotar anticipadamente la cuota del año, generando problemas sociales de insospechadas consecuencia" (SUBPESCA, 2007). Para el año 2006 el establecimiento de cuotas se realizó de forma diferenciada, teniendo trato a parte el sector pesquero artesanal el que a su vez se subdividió en tres tipos de asignación: el régimen bentónico de extracción, las áreas de manejo y el régimen artesanal de extracción. El enfoque con que ha sido tratada la pesca tanto artesanal como industrial obedece a los cambios en la percepción en cuanto a la disponibilidad de los recursos marinos que inicialmente se creía que eran inagotables, y luego se vuelven finitos y sobreexplotados.

A escala regional, la Estrategia de Desarrollo de la Región de Los Lagos en el ámbito de la economía y la producción considera que es esencial fortalecer y consolidar el sector acuícola, con el fin de hacer competitiva y dinámica esta actividad, fomentando la diversificación y reconversión de la pesca artesanal, a través de la asociatividad y la promoción de aquellas áreas con potencial productivo. Dentro de las iniciativas que planea la estrategia, se encuentran; facilitar el otorgamiento de AMERB para organizaciones de pescadores artesanales e impulsar la reconversión de la actividad pesquera extractiva a cultivadora (SECRETARÍA REGIONAL DE PLANIFICACIÓN Y COORDINACIÓN REGIÓN DE LOS LAGOS, 2000). Además el año 2001 se publica el Plan Operativo de la Política Regional de la Pesca Artesanal, Región de los Lagos, dentro de los objetivos de este plan estaban apoyar la producción pesquero artesanal, mejorar el acceso y uso eficiente del borde costero y ordenar la pesca artesanal (ROGEL, 2006). Es así como entre el 2000-2005 el Estado financió proyectos de apoyo a este sector productivo, de esta manera la comuna de Hualaihué pasó a ser parte de uno de los cinco territorios focalizados por el CARPESCA (Comisión de Asignación Regional para la Pesca), cuyo objetivo era ser una instancia de discusión y análisis del Gobierno de la Región (ROGEL, 2006); en estas circunstancias el Gobierno Regional de Los Lagos, en el marco de la implementación de la Política Nacional de Desarrollo de la Pesca Artesanal, propuso la creación de los Centros de Desembarque Pesqueros Artesanales, donde se privilegiando la asociatividad de los pescadores artesanales en torno a sus actividades productivas habituales y en la cual la implementación de políticas de desarrollo del sector, se planifiquen y se materialicen con la participación activa de los actores locales. En consecuencia se construye un nuevo centro de desembarque localizado en Pichicolo Puerto.

A nivel comunal, el PLADECO (Plan de Desarrollo Comunal) de la Comuna de Hualaihué, señala que la actividad pesquera es de carácter inestable no sólo por factores climáticos sino también por el problema de la cuota de pesca y agotamiento de la merluza (ILUSTRE MUNICIPALIDAD DE HUALAIHUÉ, 2009); por este motivo, la pesca demersal ha de complementarse con la extracción de mariscos, la producción de semillas de bivalvos y su posterior engorda. En este documento se hace gran hincapié en las ventajas comparativas de la Comuna para sostener dicha actividad resaltando la calidad de las aguas, las cuales son aptas para el cultivo de mitílidos. El objetivo principal de la pesca artesanal en la comuna según señala el PLADECO es entonces "proveer a los centros productores de productos del mar. A objeto de generar economías de escala es preferible que se establezcan unos pocos centros de desembarco en caletas aptas" (ILUSTRE MUNICIPALIDAD DE HUALAIHUÉ, 2009), esto lleva a la concentración del desembarque en pocos centros para lograr mayores volúmenes con la producción proveniente de la propia 
Comuna y también de la zona sur cordillera con lo que se facilita la negociación del precio de venta de los recursos con las plantas procesadoras (ILUSTRE MUNICIPALIDAD DE HUALAIHUÉ, 2009). En cuanto al cultivo de mitílidos el objetivo ha sido la captación de semillas y engorda mediante procesos naturales para constituir un complemento a la actividad pesquera tradicional que permita aumentar, estabilizar los ingresos y en el largo plazo ser el sustento de la Comuna (ILUSTRE MUNICIPALIDAD DE HUALAIHUÉ, 2009), por ahora en las caletas de Puntilla de Pichicolo y El Manzano sólo se han llegado a la captación de semillas, y aunque existe interés en alcanzar la engorda de los choritos, no cuentan con el suficiente capital de inversión que se requiere para ello, ya que se precisan más boyas para la flotación de las líneas de captación de semillas y fondeos de concreto para el anclaje de las mismas tal como lo señala el Informe de Resultados Estudio de Situación Base (ESBA) y la Propuesta Plan de Manejo de Isla Manzano, Región de Los Lagos (FUNDACIÓN CHINQUIHUE, 2008). El costo de instalación de una línea de captación de choritos es de $\$ 1.300 .000^{3}$ aproximadamente; para que esto sea rentable una línea de captación se hace insuficiente. Esta estrategia de desarrollo económico propuesta por el gobierno local es también la meta objetivo de los pescadores de estas dos caletas, el único inconveniente es ¿dónde conseguir el financiamiento? el PLADECO sugiere que el financiamiento debe ser obtenido por intermedio de la banca privada, empresarios, Federación de Pescadores y sindicatos, este problema se condice con los planteado en la política de administración pesquera en el que se reconoce que el sector pesquero artesanal se caracteriza por "la menor disponibilidad de medios como tecnología, capital y capacidad de gestión, para desarrollar sus unidades de negocio" (SUBPESCA, 2007), en cuanto al destino de los productos, se proyecta apuntar primeramente hacia el mercado local, luego al intercomunal, para concluir en la venta al exterior.

\footnotetext{
3 Dólar Observado a la Fecha \$ 480,22 http:/ / www. bolsadesantiago.com/web/bcs/home ( 9 de noviembre 2010) poco mas de 2.700 dólares.
}

\section{Materiales y Método}

Los instrumentos utilizados en terreno fueron; testimonios e historia oral; los cuales permiten situar al sujeto investigado como testigo, es decir, un observador directo cuenta lo que vio, lo que supo, lo que hizo o lo que conoce directamente (CANALES, 2006), con el fin de recoger información histórica relevante dentro de la caleta, para ello se concertaron encuentros con personajes claves dentro de las comunidades. También se aplicaron entrevistas no estructuradas complementadas con observación directa, con el objetivo de sondear aspectos relativos a las prácticas cotidianas de la caleta. La información obtenida a través de las entrevistas fue registrada por medio de notas y grabación (EYLES, 1998). Se aplicó también una encuesta bioeconómica ${ }^{4}$, dirigida a pescadores artesanales, pertenecientes o no a organizaciones de pesca artesanal, para estimar la estructura de costos de la pesquería, los días de extracción al año, las capturas obtenidas en cada faena, las artes de pesca utilizadas, los canales de comercialización de los productos, etc. Ésta información contribuye a conocer los procesos económico-productivos que se desarrollan en las caletas, como también los usos y apropiación del espacio marino.

Las entrevistas y encuestas tuvieron gran relevancia por el hecho de que "no son más el simple lugar de verificación de una problemática preestablecida, sino necesariamente los puntos de partida, o mejor dicho, los lugares mismos donde emerge la problematización, donde surgen las interrogaciones a las cuales se somete lo real" (SANTANA, 2003 , p. 34). Para aplicar los instrumentos antes señalados, la selección de informantes se realizó a partir del uso del muestreo en bola de nieve, solicitando a una persona o varias que sugiriera nombres de otras personas que él/ella crean estar dispuestos a hablar (EYLES, 1998, p. 41). Considerando que se trata de un estudio con enfoque cualitativo, el tamaño de la muestra fue definido a través del nivel de saturación, es decir, cuando el material se hace repetitivo en los principales

\footnotetext{
$\overline{4}$ Encuesta diseñada por Álvaro Espinoza Biólogo Marino, Apoyo Técnico del equipo investigativo Proyecto Fondecyt n. 1080665.
} 
temas detectados (EYLES, 1998) se deja de agregar información (CANALES, 2006).

Se realizó también levantamiento cartográfico en base a los datos obtenidos en las encuestas y entrevistas realizadas a los pescadores artesanales para reconocer la ubicación de las zonas de pesca también llamados caladeros (antiguos y actuales) y las especies objetivo para cada una de estas áreas, lo que sirvió para visualizar espacialmente la evolución que ha tenido el uso del espacio marino como también las prácticas productivas ligadas a la pesca artesanal en las caletas.

La investigación se realizó de acuerdo a dos escalas de análisis: a) escala espacial; b) escala temporal. En tanto las unidades sociales de análisis corresponden a los Sindicatos de Pesca Artesanal.

Se identificaron 2 grandes periodos de Prácticas y Usos del Espacio Marino constituidos por un total de 4 Momentos dentro del desarrollo de la actividad en las caletas (Ver Figura n. 1).

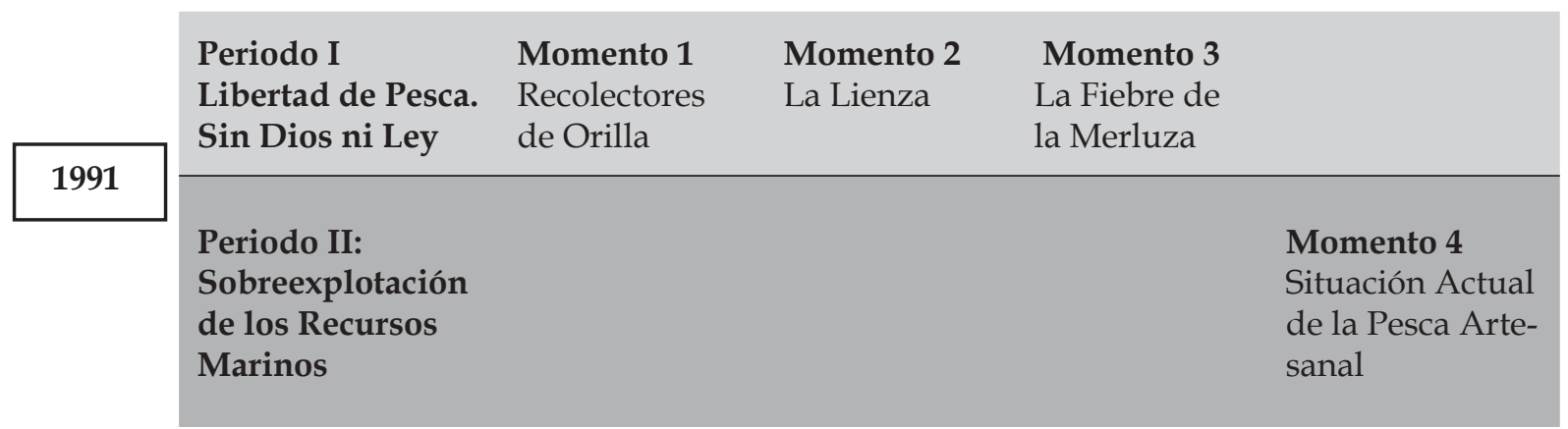

Figura 1 - Prácticas y Usos del Espacio Marino.

Fuente: Elaboración Propia

El punto de inflexión elegido para el establecimiento de los periodos es el año 1991 con la promulgación de la Ley General de Pesca y Acuicultura, en tanto las fechas de inicio consideradas para la definición de los Momentos corresponde a la información más antigua que los informantes pudieron rememorar, con esta información fueron confeccionadas posteriormente las cartografías.

La recolección de información secundaria fue otra actividad que complementó la metodología, esta se refirió a información recopilada en organismos de administración pública a nivel regional y comunal relacionados con la pesca artesanal, fundaciones, sindicatos de pescadores, consultoras, entre otras. También se hizo uso de información Censal ${ }^{5}$ la que contribuyó a caracterizar socioeconómicamente la población de las caletas.

Para el tratamiento de la información obtenida a partir de entrevistas se aplicó análisis sociológico del discurso, para conocer las relaciones existentes entre las estructuras de significación y el contexto social y/o político de las caletas (MURILLO, 2004). Se partió de la base que el discurso es socialmente aceptado, en el momento que es capaz de representar en su contenido algunos presupuestos sociales (MURILLO, 2004).

Dada la diversidad en las prácticas pesquero-artesanales como en el uso del espacio litoral, se aplicó análisis comparativo, esto significa que se estudió la misma problemática en dos unidades territoriales (Caletas de Pesca Artesanal). A priori se puede distinguir que ambas caletas se encuentran en una etapa de transición de la escaza mecanización de sus prácticas, a un sistema productivo controlado y tecnificado, en el cual se hace necesaria una mayor dotación de capitales (RUIZ; MADRID, 1997).

\footnotetext{
$\overline{5}$ Censo de población 2002.
} 


\section{Resultados: Prácticas y usos del Espacio Marino}

\section{PERIODO I: Libertad de Pesca. Sin Dios ni Ley}

Prácticas y usos del espacio marino antes de la Ley General de Pesca (1991)

\section{Momento 1: Recolectores de Orilla}

El Manzano: Antes de la década del sesenta era común que la gente de la caleta se dedicara a mariscar. Sacaban choritos, cholgas, navajuelas y almejas; para la extracción se utilizaba una herramienta llamada gualato ${ }^{6}$, en aquellos años aun no era muy común el buceo con escafandra ${ }^{7}$, los mariscos eran vendidos desconchados denominados localmente como "mariscos en carne" para aquello cocían los mariscos y luego los llevaban hasta las fábricas de Calbuco. La extracción de los mariscos se hacía por el Fiordo Llancahué y Quintupeu, también viajaban hasta los canales cerca de Ayacara, Loyola y el Golfo de Ancud, para ello las salidas duraban entre 2 y 3 meses.

Puntilla Pichicolo: En la década del sesenta hasta mediados de los setenta, se extraían; cholgas, choritos y choro maltón (Tagelus dombeii), para ello viajaban hasta el archipiélago de las Guaitecas por temporadas de seis meses, también se trasladaban a otros lugares en embarcaciones llamadas faluchos de 9 metros de eslora, con propulsión a remo, el zarpe se realizaba en Calbuco, empleaban el equipo de escafandra para la extracción de mariscos. Las empresas procesadoras de mariscos iban hasta estas zonas a retirar la pesca para llevarla hasta las plantas en Calbuco. Hubo quienes incluso se trasladaron hasta Punta Arenas a trabajar.

En el Momento 1 se logran identificar elementos comunes en los discursos de ambas caletas, como son las estadías prolongadas en zonas distantes como Ayacara donde extraían recursos bentónicos.

\section{Momento 2: La lienza y el gran castigo de Chile}

El Manzano: El róbalo (Eleginops maclovinus) ya se extraía para finales de los años treinta, según lo que recuerdan los entrevistados. El arte de pesca utilizado era el espinel el cual se confeccionaba con

Un pasto que antes llamábamos las cortaderas, eso lo machacábamos y con eso hacíamos cabitos, eso después lo amarrábamos a los anzuelos con crin de caballo, se torcía el crin y ahí se amarraba el anzuelo, con carnada de camarón, un buen día en veces nos iba bien y podía sacar medio saco uno, eran róbalos grandes, esos se oreaban, se vendían ahumados, me los llevaba pa "Puerto 8 o pa" Calbuco [sic] (ver Cartografía n. 2).

\footnotetext{
6 Gualato: azada pequeña de punta ojival usada indistintamente en labores agrícolas y para mariscar (CÁRDENAS y HALL, 2005).

7 Durante el siglo XX se produjo la mayor transformación tecnológica en la explotación de recursos bentónicos de la X Región de Los Lagos, lo que fue apoyado por la incorporación del sistema de buceo con escafandra o traje de buceo mejorado de Siebe a la actividad mariscadora. Anteriores a los buzos mariscadores, los equipos de buceo -y, por tanto, también los buzos- trabajaban sólo en actividades militares o de salvataje comercial, sin prestar mayor atención a mariscar buceando (CHAMBEAUX; MICHEL; RETAMALES, 2009, p. 31).
}

\footnotetext{
8 Puerto Montt.
} 


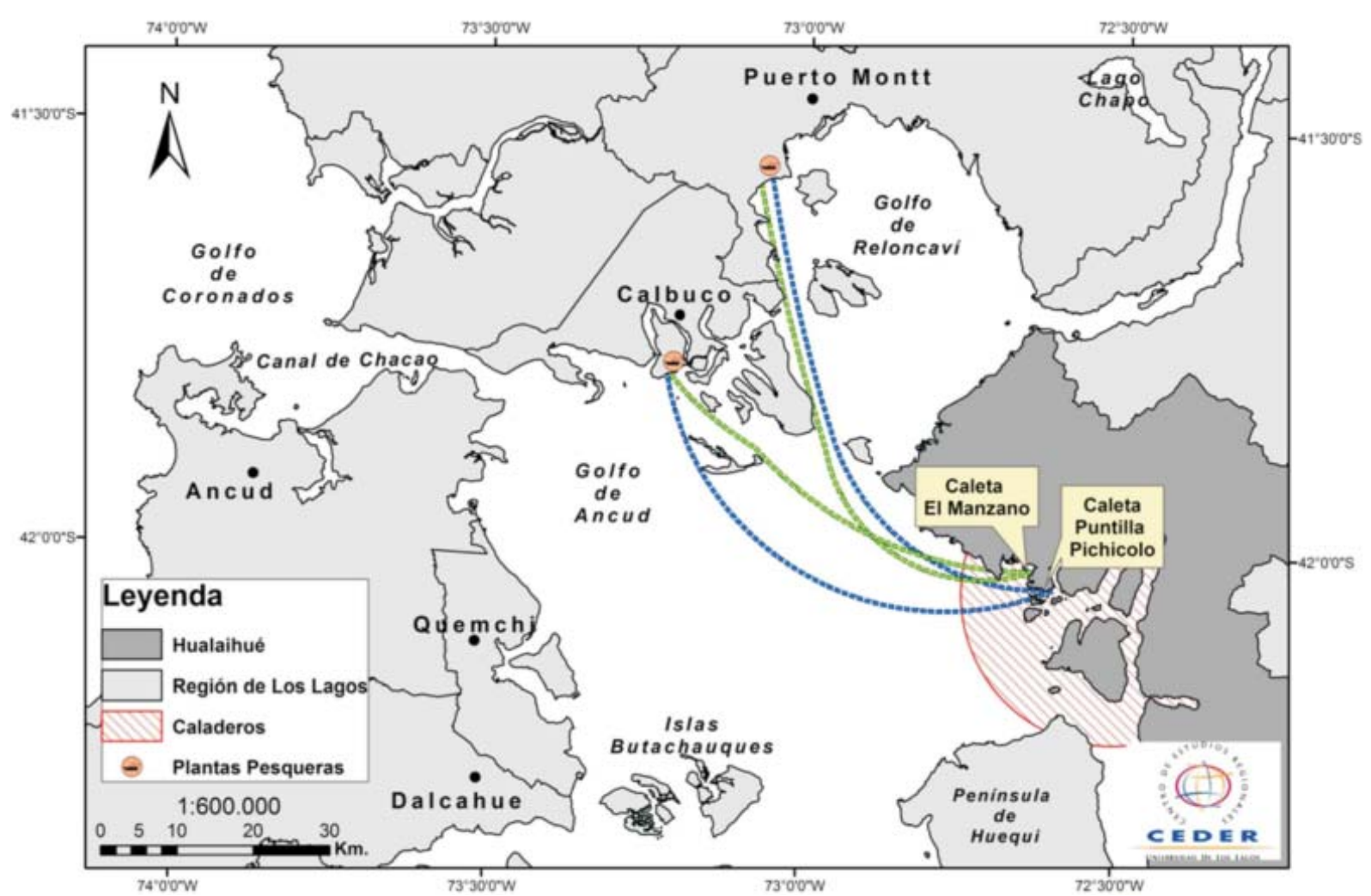

Cartografía 2 - La lienza y el gran castigo de Chile

Fuente: Elaboración Propia

Cuentan que el terremoto del año 1960 ("el gran castigo de Chile") afectó a los camarones ya que las pacetas donde habían que eran blandas ya no hay se quedó todo duro después del sismo, se removió todo y la arena se puso dura, ya el pescado por ejemplo el camarón que había tantísimo ya no hay, se murió, unos se murieron ahí debajo de la tierra otros alcanzaron a salir.

El róbalo se intercambiaba ahumado, además de esta actividad se comercializaba leña bajo el sistema de trueque denominado localmente como "al cambio" entre los familiares, por otros productos comestibles, que transportaban en embarcaciones de propulsión a vela.

A partir del Gobierno de Jorge Alessandri Rodríguez en 1958 hasta Salvador Allende se impulsa una política de fortalecimiento de la salud pública la cual buscaba combatir el raquitismo en los niños, aprovechando el aporte vitamínico del aceite de hígado de pescado se comenzó a distribuir de forma gratuita en las escuelas (Instituto de Salud Pública de Chile), este y otros factores incidieron en la explotación del bacalao (Dissostichus eleginoides) rico en vitamina $\mathrm{D}$, además del tollo (Mustelus mento), el cual se sacaba con lienzas ${ }^{9}$ de algodón, luego el congrio (Genypterus chilensis). Con el tiempo sólo el tollo fue apetecido comercialmente, esto se potenció según relatan los habitantes con la instalación de una fabrica procesadora de bacalao "se le vendía a lo que llamábamos la pulpería, al cacique Castilla, español"10 localizada en Isla Llanchid (ver Cartografía n. 2), así lo cuentan los habitantes de la caleta.

Lo llevábamos el pescado allá y ellos lo transformaban en bacalao, pescaban, él se los compraba, pescaba el congrio lo abría los salteaba, lo salaba bien salado, eso quedaba... no se notaba donde estaba el pescado por la sal, lo cocía la sal, y eso después cuando ya estaba unos 15 a 20 días en la sal, se sacaba al sol lo secaba con secador, eso después seco lo pesaba y hacia fardos como quien hace fardos de cuero. ${ }^{11}$

\footnotetext{
9 La pesca con lienza consiste en un hilo con uno o varios anzuelos que pueden ser usados desde la orilla del mar o desde una embarcación.

${ }^{10}$ Entrevista con Don Gustavo Maldonado (El Manzano), realizada entre Marzo-Abril.

${ }^{11}$ Entrevista con Don Gustavo Maldonado (El Manzano), realizada entre Marzo-Abril.
} 
Las mujeres recuerdan haber participado activamente en estas tareas, ellas eran quienes le sacaban el cuero, para luego vender la carne la cual transportaban en pequeñas embarcaciones a remo hasta la isla Llanchid, una vez que recibían el pago en este mismo lugar podían adquirir sus víveres y otros artículos, para ese entonces no existía otra opción, ya que en El Manzano no habían más almacenes, debido a que sólo era un caserío. Este negocio finalizó, una vez "que se cortó la exportación de bacalao para Valparaíso ya no siguieron con el bacalao", según los testimonios recogidos en ambas localidades, el negocio quebró y los dueños se retiraron de la isla dejando en completo abandono las instalaciones para el procesamiento del pescado y un aserradero.

Finalizada la explotación del tollo, volvieron a pescar congrio. Las zonas de pesca para este recurso (ver Cartografía n. 2) se encontraban desde la Isla de Chiloé hasta Linguar frente a Achao, el Golfo de Ancud además del sector de Buil. En este periodo se comenzaron a utilizar las lanchas a motor.

Puntilla Pichicolo. A principios de los sesenta existió una planta de aceite de bacalao en la zona, el dueño era un español que compraba exclusivamente el hígado del tollo, para transformarlo en aceite de bacalao. Luego entre finales de la década de los sesenta y principios de los setenta, el tollo era vendido a otro español que vivía en la Isla Llanchid (ver Cartografía n. 2), dicha empresa compraba la carne del tollo, congrio, merluza (Merluccius australis), mantarraya (Raja chilensis), etc., no importaba la especie todo era comprado para "hacerlo bacalao" [sic] el resto de carne se botaba, ambos peces eran capturados con pinche o lienza, el congrio se pescaba de noche, en cada jornada se podía sacar entre 30 y 40 kilos. La planta de secado de pescado conocida como secaduría o saladero duró cerca de 8 años, durante el tiempo que funcionó la gente llegaba desde otros sectores de Hualaihué para vender sus productos, además en este mismo lugar podían comprar sus víveres o cualquier otra cosa que necesitasen.

La llegada de extranjeros a la zona dinamizó la economía local, no sólo como fuente de trabajo, sino también al alero de estos empresarios podían abastecerse de los productos necesarios para su subsistencia.
Momento 3: La Fiebre de la Merluza (Mediados de 1970 - 1991)

El Manzano: La merluza se comenzó a explotar en la caleta durante los años ochenta ${ }^{12}$, hasta antes de esta década no se pescaba merluza ya que

Nadie comía la merluza aquí antes como ahora, se comía el róbalo y el congrio nadie se aplicaba porque decían que no era bueno ¿ahora quién come una merluza? lo compran, lo piden porque no lo tienen, nadie creía que esa era un pescado tan bueno. ${ }^{13}$

En principio el arte de pesca utilizado era el pinche o lienza, al que ataban un plomo con un alambre y ponían el anzuelo con la carnada, la lienza era confeccionada con algodón, este sistema terminó con la llegada de pescadores de la ciudad de Valdivia, quienes utilizaban los espineles, acto seguido los pescadores de El Manzano imitaron este sistema, aprendieron el arte y adquirieron los materiales, esta innovación implicó favorablemente en el aumento de las capturas, ya que con el sistema anterior todo era más lento puesto que trabajaban con sólo una lienza a cada lado del bote. En un comienzo cada pescador llevaba consigo 6 espineles, luego aumentaron entre 10 y 12, con 18 anzuelos cada uno, en la actualidad la gran mayoría usa en promedio 40 espineles con 25 y 30 anzuelos cada uno, los espineles utilizados son de monofilamento y verticales. La biodisponibilidad de la merluza en aquel tiempo era mucho mayor a la que existe en la actualidad.

Hasta antes de la Ley General de Pesca y Acuicultura (1989), la merluza era comercializada por pieza o unidad, el precio se asignaba de acuerdo al tamaño, existían distintas categorías; chica, grande, extra y super sobre los $65 \mathrm{~cm}$. Cada medida tenía precios diferenciados, bajo los $60 \mathrm{~cm}$. de talla (llamada entre los pescadores como Merluza Pitufa) no era comercial.

Se viajaba cerca de 25 minutos para llegar a los caladeros (ver Cartografía n. 3) y

\footnotetext{
${ }^{12}$ Desde mediados de los años setenta el esfuerzo pesquero se concentró en la explotación de la merluza austral, en tanto la pesca artesanal se incorporó con fuerza a mediados de los ochenta (PEÑA; BUSTOS; PÉREZ, 2005).

${ }^{13}$ Entrevista con la esposa de Don Gustavo Maldonado (El Manzano), realizada entre Marzo-Abril 2009.
} 
en tan sólo una hora cargaban el bote, en cualquier lugar que lanzaran los espineles podían encontrar pescado, en ocasiones cuando trabajaban en el sector de Ayacara podían ir hasta dos veces al día sacando entre 300 y 500 kilos diarios sólo de merluza. Un mal día de pesca consistía en una captura de 200 kilos, otros pescadores que no tenían lanchas a motor iban remolcados, cada lancha remolcadora podía llevar 7 lanchas hasta Ayacara, Poyo, Hueque, Buil, Islas Butachauques, Golfo de Ancud, etc.

Desde que comenzaron a pescar merluza, los pescadores del Manzano han tenido que lidiar con las flotas de pesca industrial, las cuales se localizan en el sector de la Boca del Guafo al sur del mar interior de Chiloé (ver Cartografía n. 4), es en este lugar donde los cardúmenes de merluza y el resto de especies hacen su entrada al mar interior, por lo tanto, las embarcaciones interceptan los cardúmenes, pescándolos mediante el uso de la pesca de arrastre ${ }^{14}$, los pescadores detectan la presencia de los industriales aun cuando no los ven directamente ya que cuando esto no ocurre dicen que el pescado llega a la misma caleta.

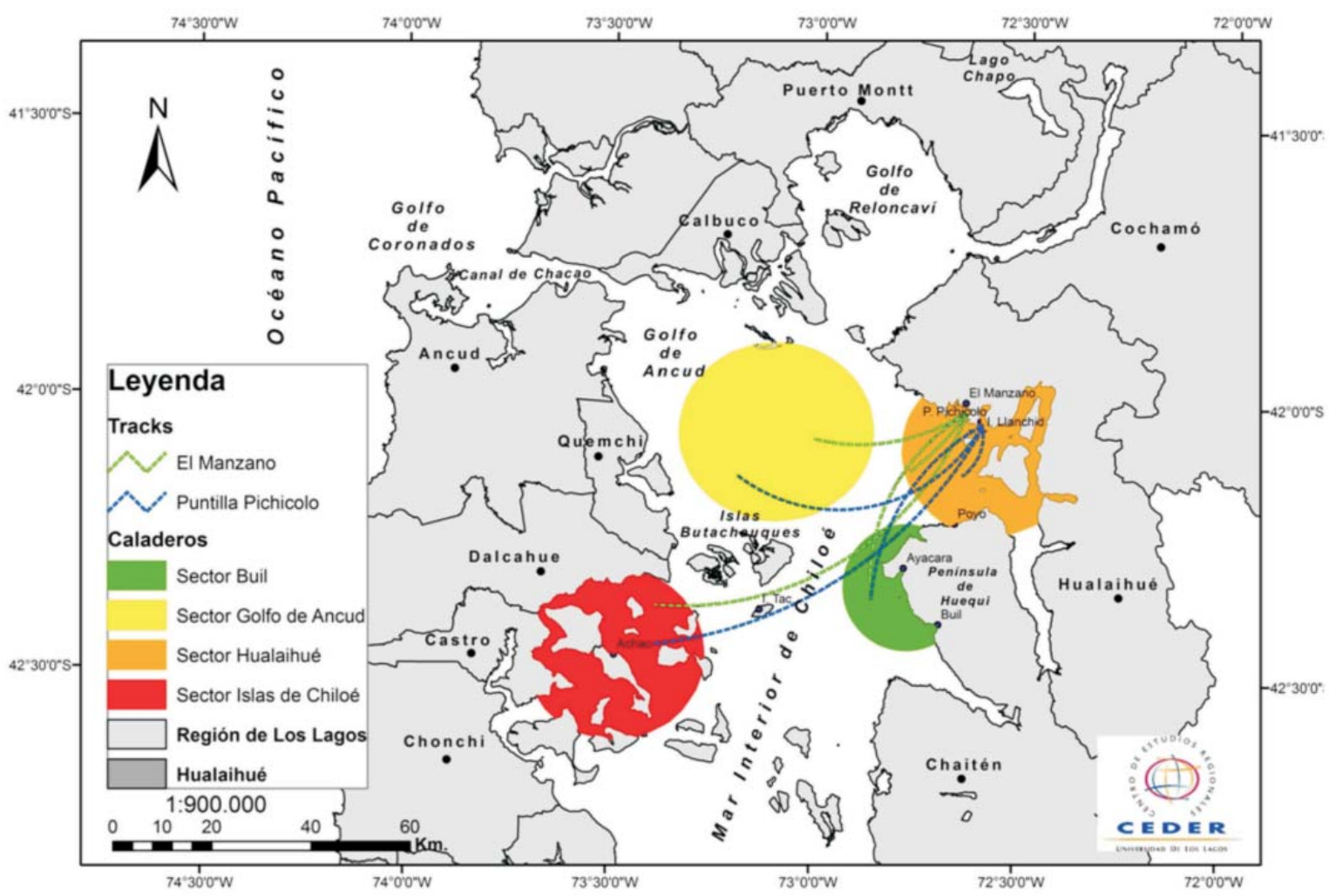

Cartografía 3 - La Fiebre de la Merluza

Fuente: Elaboración Propia

\footnotetext{
${ }^{14}$ Este aparejo de pesca consiste en una red de arrastre de fondo construida con forma de cono y arrastrada por una o dos naves barriendo el fondo marino, comúnmente utilizado en los barcos factorías (LEY..., 1989; SUBSECRETARIA DE PESCA, 2003).
} 
Recuerdan que en una ocasión un barco se hundió con todo su cargamento, la causa:

Por ambiciosos tiraron sus redes, y sus redes se cargaron hasta cuando las quisieron subir y el barco no dio más y se hundió, no se supo más, recogían con arrastre pescados chicos y grandes por eso se perdió la merluza, se escapó y ya no se encontró más. ${ }^{15}$

A comienzos de los ‘90, los mismos sindicatos comenzaron a notar que el recurso se estaba perdiendo por la sobre captura, hasta ese momento pensaban que "iba a ser una cosa que iba a ser interminable, como se daba al principio abundante" ${ }^{16}$, eran demasiados los botes que estaban trabajando, los pescadores provenían de distintas zonas tales como Chiloé y Calbuco por lo cual "la comuna de Hualaihué era un caos, no había dónde trabajar"17, se hacía indispensable regular la extracción, para ello se propuso la incorporación de un sistema de cuotas de extracción o por fechas de pesca, se eligió la primera alternativa, esto permitió ordenar la explotación del recurso; en 1991 con la entrada en vigencia de la Ley General de Pesca y Acuicultura se impuso una cuota anual de captura, esta cuota era repartida proporcionalmente entre las pesquerías industriales y artesanales, las que a su vez eran redistribuidas en cuotas individuales, este régimen fue complementado por otras regulaciones tales como vedas, cierres de áreas, restricciones a las artes y capacidad de pesca, áreas de operación exclusiva para la pesca artesanal, etc. (PONTIFICIA UNIVERSIDAD CATÓLICA DE CHILE, 2009).

Por otra parte, se dejó de vender la merluza por tamaño (grande, super y extra) esto desencadenó que la merluza de menos de 60 cm de talla denominada "pitufa", se volviera un recurso comercial. Los pescadores piensan que este cambio tuvo un efecto negativo pues “ahora la merluza muere injustamente, la Ley no debería permitir que en ninguna parte del país compren ese pescado" ${ }^{18}$. El primer año

\footnotetext{
${ }^{15}$ Entrevista con Don José Mariman (Puntilla Pichicolo), realizada entre Marzo-Abril.

${ }^{16}$ Entrevista con Don José Luis Maldonado (El Manzano), realizada entre Marzo-Abril.

${ }^{17}$ Entrevista con Don José Subiabre (El Manzano), realizada entre Marzo-Abril.

${ }^{18}$ Entrevista con Don Nivaldo Gutiérrez (El Manzano), realizada entre Marzo-Abril.
}

que se implementó el sistema de cuotas, se autorizó la extracción de 400 kilos mensuales para cada armador artesana $1^{19}$, con el tiempo esta cantidad fue disminuyendo hasta llegar a los 300 kilos que hoy se extraen.

Puntilla Pichicolo: Desde antes de los setenta ya se pescaba Merluza en la caleta, para la captura del recurso se utilizaban lienzas de algodón que eran teñidas con la corteza del ulmo (Eucryphia cordifolia), quedando de color café, esta práctica se realizó hasta principios de los años setenta, cuando un español llegó a la zona con la empresa INCOMAR, en aquel tiempo llamaban experimento a los espineles, primero los hicieron "con cabos gruesos y después con monofilamentos ${ }^{\prime 20}$ esto permitió mejorar la producción.

Las zonas de pesca (ver Cartografía n. 3) incluían el Estero Pichicolo e Isla Llanchid, también iban al sector de la isla Llancahué por el Canal de Cholgo. La merluza que se sacaba era llevada a la planta que estaba en Calbuco, con el tiempo fue llevada directamente a Puerto Montt donde se sellaban en cajas de plumavit para ser exportadas a España ${ }^{21}$, para ese entonces dos personas hicieron función de intermediarios, comprando la pesca para llevarla a la planta, uno de ellos era un habitante de la caleta Puntilla Pichicolo.

Según relatan los pescadores en $1983^{22}$ se comenzó a exportar merluza a Japón, Austria e Italia, hasta antes de la llegada de los

\footnotetext{
${ }^{19}$ Armador: es el pescador artesanal, la persona jurídica o la comunidad, en los términos que establece el Código Civil, propietaria de hasta dos embarcaciones artesanales, que en su conjunto no podrán tener una capacidad de bodega que exceda de ciento sesenta metros cúbicos (LEY..., 1989).

${ }^{20}$ Entrevista con Don José Edenubio Gueicha (Puntilla Pichicolo), realizada entre Marzo-Abril 2009

${ }^{21}$ En los años ochenta empresarios españoles llegaron a Chile para comercializar la merluza austral en formato fresco-refrigerado y congelado, en ocasiones, esta especie es vendida en España como merluza de pincho (Merluccius merluccius) comúnmente conocida como pescadilla o pijota en dicho país (PEÑA; BUSTOS; PÉREZ, 2005).

${ }^{22}$ Durante el periodo 1980-1988 el desembarque de Chile creció a una tasa media anual del 7,9\% y un aumento similar de la producción y las exportaciones se observó en el mismo período, las cuales crecieron a tasas medias anuales del 9 y 11,3\% respectivamente. Este ritmo de crecimiento llevó a fines del decenio, a una producción de 1,2 millones de toneladas y a exportaciones por un valor superior a los US\$900 millones (ZULETA, 1990).
} 
españoles la merluza era sólo para autoconsumo, algunos pescadores recuerdan que "ni caso se le hacía a la merluza, moría en la playa se la comían los pájaros, bien poco se comía la merluza y los españoles trajeron todos los materiales de Canadá los espineles todos los materiales" ${ }^{\prime 2}$.

La biodisponibilidad de la merluza ha disminuido, así lo notan los pescadores pues dicen que hace 10 años atrás un buen pescador sacaba entre 400 y 500 kilos en un día, ahora en buenas condiciones sacan los 300 kilos de la cuota en una jornada de pesca. Antes de que se aplicara el sistema de cuotas "se pensaba que no se iba a terminar, ahora que están las vacas flacas ${ }^{24}$ uno se acuerda de que todo se termina en esta vida" ${ }^{25}$.

Al igual que en el caso de caleta El Manzano, los pescadores de la Puntilla tienen un cuidado especial con la merluza pitufa: cuando sube viva atrapada en los anzuelos, la toman y con sus propias manos aprietan el abdomen del pez con la idea de botarle el aire y luego la devuelven al mar; esta acostumbre fue adquirida a finales de los ochenta cuando comenzaron a notar que la merluza austral ya no salía en la misma cantidad de antaño, cada vez les era más difícil llenar sus botes, por lo mismo para que no continuara desapareciendo, en un acto de autorregulación y conservación del recurso comenzaron a practicar esta técnica, pues reflexionaron que si la pitufa retorna al mar "va a poder crecer más y después cuando se cría se podrá vender a otro precio, hay que cuidarla, con los otros recursos marinos ${ }^{\prime 26}$. Sin embargo, siguen culpando a los pescadores industriales de la desaparición de la merluza ya que a su juicio ellos "barren con todo, no respetan nada, suben hasta las crianzas ${ }^{27 \prime \prime 28}$.

\footnotetext{
${ }^{23}$ Entrevista con la esposa de Don Gustavo Maldonado (El Manzano), realizada entre Marzo-Abril 2009.

${ }^{24}$ Dicho popular utilizado para referirse a los periodos de escases; su opuesto es las vacas gordas para hacer alusión a aquellos periodos de abundancia económica.

${ }^{25}$ Entrevista con Don José Marimán (Puntilla Pichicolo), realizada entre Marzo-Abril 2009.

${ }^{26}$ Entrevista con Don Gustavo Maldonado (El Manzano), realizada entre Marzo-Abril 2009.

${ }^{27}$ El entrevistado hace referencia a la pesca de arrastre que genera una fuerte degradación del fondo sobre especies hidrobiológicas, mediante la captura y remoción de pequeños organismos y recursos no objetivo, los cuales usualmente son descartados al mar (SUBSECRETARIA DE PESCA, 2007).

${ }^{28}$ Entrevista con Don Nivaldo Gutiérrez (El Manzano), realizada entre Marzo-Abril 2009.
}

En la comuna de Hualaihué existen 14 caletas decretadas con un total de $416 \mathrm{em}-$ barcaciones registradas, contando los botes a motor, remo y las lanchas, a cada una de estas embarcaciones les corresponde una parte de la cuota regional de pesca que a su vez se subdivide en zonas y subzonas, los pescadores recuerdan que la primera vez tuvieron una cuota de 520 kilos aproximadamente.

\section{PERIODO II: Sobreexplotación de los Recursos Marinos}

Prácticas y usos del espacio marino posteriores a La Ley General de Pesca (1991)

\section{Momento 4: Situación Actual de la Pesca Artesa- nal (1991-2009)}

El Manzano: En el caso de la pesca demersal, cada embarcación trabaja con dos a tres tripulantes a bordo y las ganancias son repartidas a través del sistema de "partes" 29 . Lo capturado es vendido en playa a intermediarios ${ }^{30}$ también llamados proveedores los cuales fijan los precios y les proveen de combustible, carnada e incluso materiales para renovar sus artes de pesca, estos intermediarios compran la producción de los pescadores para luego llevarla a las plantas pesqueras de Puerto Montt, sólo algunos pescadores venden sus productos en la feria de Hornopirén que se instala los días sábados.

Sin importar el Sindicato de procedencia, el producto objetivo es la Merluza del Sur o Austral la cual se pesca bajo el sistema de cuota equivalente a 300 kilos por armador ${ }^{31}$.

\footnotetext{
${ }^{29}$ Del total de las ganancias, se descuentan los gastos asociados a la salida de pesca (combustible, aceite para el motor, etc.) y de mantención de la embarcación, el restante se divide en tres partes una para el armador y las otras dos para los tripulantes

${ }^{30}$ Los intermediarios forman parte del segundo eslabón de la cadena productiva del pescador, este grupo son quienes llegan a la rampa esperando comprar los productos obtenidos de las faenas pesqueras, ellos son quienes fijan los precios, los cuales pueden tener fluctuaciones diarias que no obedecen a factores asociados a la demanda ni la calidad del producto sino como plantean Allut y Freire (2006, p. 2) "sino a otras causas como: el número de compradores presentes en la subasta, acuerdos internos entre ellos, etc. [...] de este modo, se mantiene latente la relación cautiva de un sector respecto al otro y el control sobre el escenario".

${ }^{31}$ Información recabada a través de la encuesta bioeconómica.
} 
La cuota debe ser extraída un par de días en el mes, no siempre es posible extraerla, en meses de invierno cuando el tiempo se hace escabroso es imposible salir a calar, dadas las desfavorables circunstancias climáticas muchos optan por acumular la cuota mensual para extraerla durante la temporada estival, otros prefieren vender su cuota, ellos afirman que año tras año la cuota ha ido disminuyendo en tanto los precios se mantienen.

El mes de agosto corresponde al mes de veda biológica de la merluza establecido por el Servicio Nacional de Pesca (SERNAPESCA), sin embargo, los pescadores indican que la merluza no se reproduce en agosto, sino entre septiembre y principios de octubre.

El arte de pesca utilizado para la extracción de la merluza es el espinel vertical ${ }^{32}$, antiguamente se utilizaba la lienza, pero a medida que el recurso comenzó a escasear resultó más eficiente el uso de espineles. Como carnada se usa pejerrey o sardina las que suelen comprar a los bolincheros ${ }^{33}$, como complemento utilizan la Huilca ${ }^{34}$ una especie acompañante que sale cuando pescan merluza, congrio o mantarraya; para estos fines utilizan la jibia (Dosidicus gigas) y la anchoveta (Engraulis ringens). El horario de zarpe es entre las 5 y las 6 de la mañana para comenzar a calar cerca de las 7 u 8 AM; esperan hasta el medio día para recoger los espineles.

El caladero por excelencia es el sector del Golfo de Ancud, otros caladeros se encuentran en las Islas Butacheuques y las Islas Tac (ver Cartografía n. 4). Hoy en día no se alejan mucho de la caleta, ya que los costos incurridos en el transporte a otras zonas de pesca no son recuperados con la pesca, cada día los recursos son más escasos en compa ración a lo ocurrido antiguamente cuando viajaban a la zona de Ayacara o a las Guaitecas donde podían extraer en cada salida más de 500 kilos de merluza por jornada de trabajo, más del doble de lo que hoy tienen asignada para el mes, hoy se considera positivo cuando en una salida pueden extraer 200 kilos de merluza pero en promedio sólo sacan 100 kilos. Aun cuando las zonas de pesca son las mismas para las ambas caletas, no existen mayores conflictos entre los pescadores de El Manzano y Puntilla Pichicolo, ni tampoco entre sindicatos de la misma caleta.

Acabada la cuota salen en busca de especies secundarias como la mantarraya y el congrio. El arte de pesca utilizada para la extracción de dichos recursos es el espinel de fondo $\mathrm{u}$ horizontal ${ }^{35}$, no hay sistema de cuotas para estas especies, tampoco tienen claridad de la fecha de veda biológica aunque algunos pueden llegar a afirmar que la mantarraya tiene veda en noviembre y el congrio en septiembre.

Si bien, hoy la explotación de los mariscos se realiza por intermedio de figuras de administración pesquera (principalmente, AMERB y Concesiones Acuícolas) no quiere decir que la recolección de mariscos de orilla haya quedado en el olvido. Aun se realiza marisqueo en las zonas libres (ver Cartografía n. 5), pues la recolección de mariscos siempre ha representado una actividad complementaria a la pesca demersal, aun cuando pocas personas la practican para vender, todos continúan recolectando cholgas, choritos y almejas para el autoconsumo. La gente sólo sale a mariscar para vender "cuando les compran las almejas y navajuelas ${ }^{36}$ frescas en Puerto Montt" ${ }^{37}$.

\footnotetext{
${ }^{32}$ Los espineles y/o palangres verticales son un arte de pesca en que el pez se extrae usando carnadas artificiales o naturales dispuestas en anzuelos atados al extremo de una línea o reinal que a su vez va atado a una línea madre que queda de forma vertical sobre el fondo y desde el cual se engancha el pez (SUBSECRETARIA DE PESCA, 2007; ARANA y VEGA, 2000).

${ }^{33}$ Pescadores de carnada (pejerrey, sardina) que se valen de redes de cerco también llamadas redes bolincheras para la extracción de estas, los "bolincheros" provienen de la localidad de Hualaihué Puerto.

${ }^{34}$ Merluza de Cola (Macruronus magellanicus).
}

\footnotetext{
${ }^{35}$ A diferencia del espinel vertical, en este caso la línea madre queda calada en forma paralela al fondo marino.

${ }^{36}$ Nombre científico: Tagelus dombeii

${ }^{37}$ Entrevista con Don Luis Ávila Fernández (El Manzano), realizada entre Marzo-Abril 2009.
} 


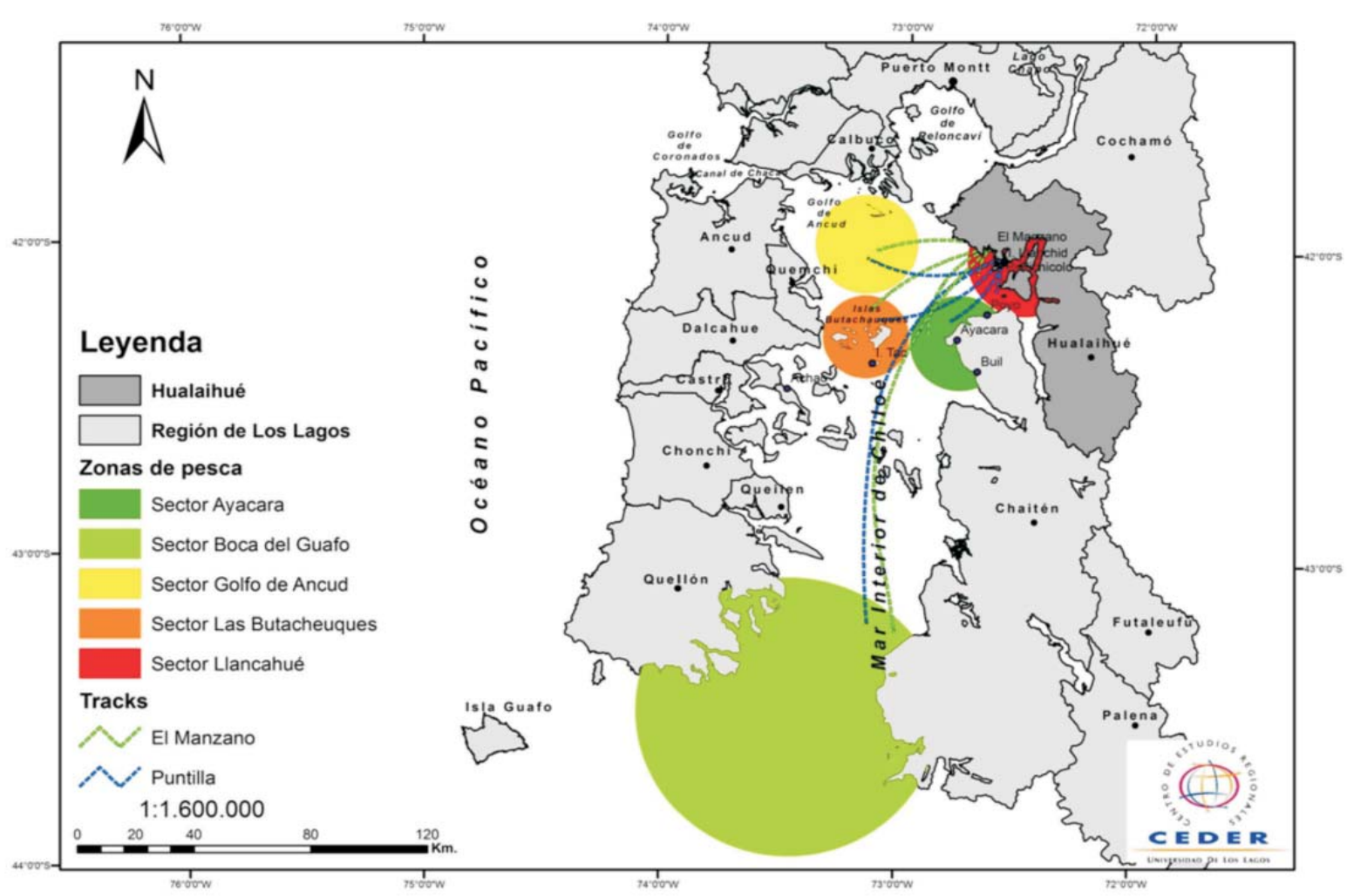

Cartografía 4 - Situación Actual de la Pesca Artesanal Fuente: Elaboración Propia

Una de las figuras de administración pesquera más importantes en estas caletas son las AMERB, a cargo de las organizaciones de pescadores. En las AMERB existen bancos naturales de recursos bentónicos, teniendo las organizaciones de pescadores derecho a explotar de forma exclusiva los recursos existentes en dicha zona (SUBSECRETARIA DE PESCA, 2007) (ver Cartografía n. 5). De los tres sindicatos existentes en la caleta El Manzano, sólo el sindicato San Juan no tiene AMERB puesto que no lograron coordinarse a tiempo para optar a un área de manejo. Los otros dos Sindicatos tienen AMERB, las que son utilizadas principalmente para tener colectores de semillas de choritos. La captación de semillas es buena, las aguas de la caleta son óptimas ya que no están contaminadas, por ello "todo lo que produce el mar va a estar en perfectas condiciones" ${ }^{\prime \prime}$. En ocasiones, los co lectores se hunden por el peso excesivo, para evitar esta situación se hace necesario invertir en una mayor cantidad de boyas (flotadores); al no contar con los recursos necesarios han tenido que optar por ralear o desdoblar las semillas para así disminuir la densidad de choritos en los colectores y eliminar la fauna acompañante, esto ayuda a disminuir el peso y aumentar la flotabilidad. Los colectores no sólo son propiedad de los sindicatos sino también, existen Concesiones Acuícolas $^{39}$ en la caleta (ver Cartografía n. 5). La captación de semillas de choritos tiene dos cosechas al año; las semillas son vendidas principalmente a planteles mitilicultores de la isla de Chiloé.

\footnotetext{
${ }^{38}$ Entrevista con Don José Subiabre (El Manzano), realizada entre Marzo-Abril 2009.

${ }^{39}$ Es una figura administrativa que otorga a una persona natural o jurídica los derechos de uso y goce de una columna de agua por tiempo indefinido, para que se realicen allí actividades de acuicultura (LEY..., 1989).
} 


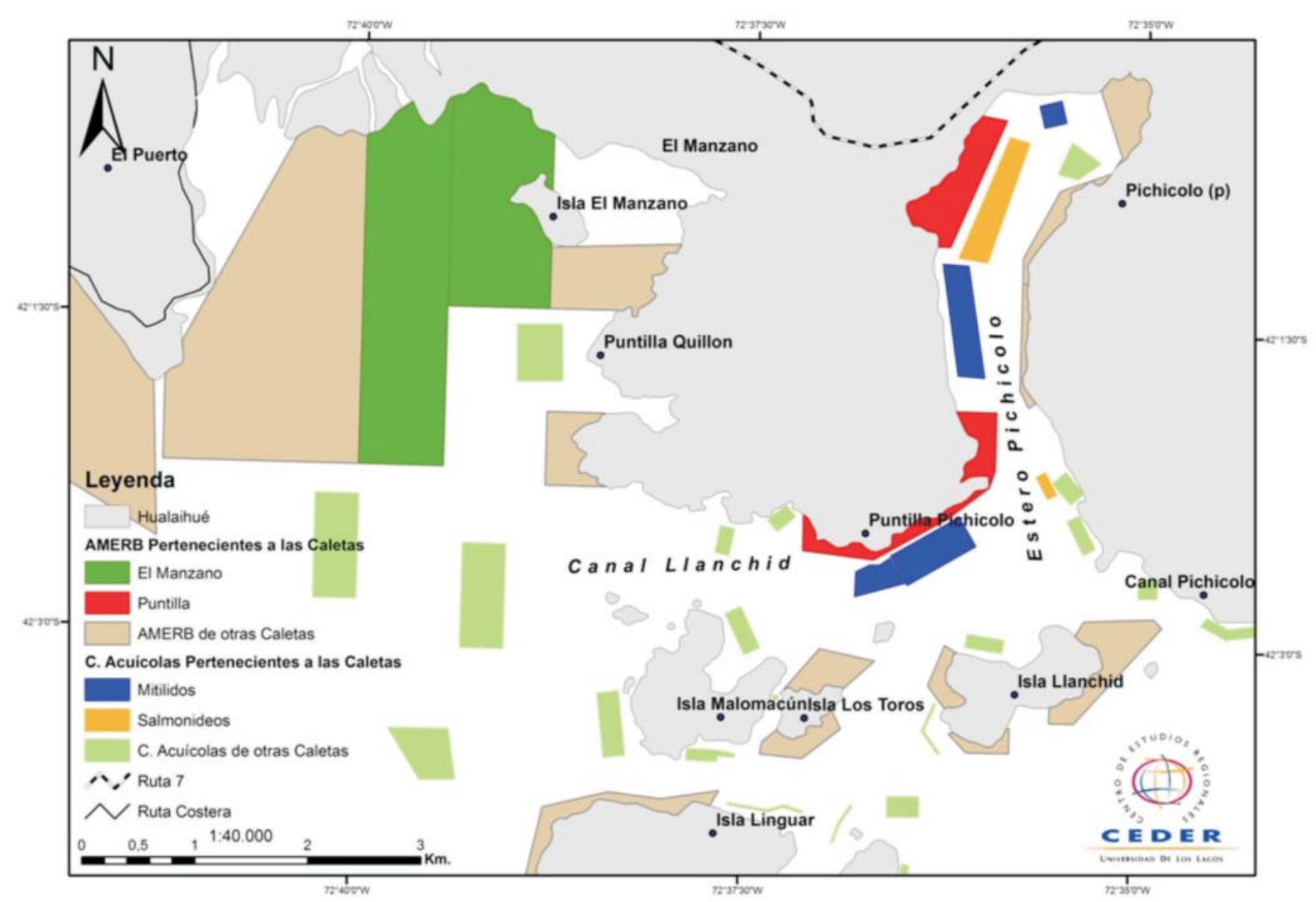

Cartografía 5 - Actuales usos del espacio marino en las caletas

Fuente: Elaboración Propia

Las AMERB son utilizadas como fachadas legales en las cuales las organizaciones de pescadores usan para contener en su interior líneas colectoras de mitílidos. En el caso del sindicato El Manzano, se encuentran trabajando en sociedad con una empresa, el Sindicato es quien hace la postulación, los trámites para obtener la administración de la AMERB y la mano de obra, tal como ellos mismos lo admiten "nosotros les trabajamos a ellos, pero son los dirigentes los que administran" ${ }^{40}$ por su parte la empresa pone el capital para invertir en los colectores y llevar la contabilidad, además constantemente están visitando el área para vigilar el negocio, los miembros del sindicato ven en este negocio una fuente de trabajo seguro, afirman que así por lo menos "hay trabajo para todos, y todos vamos a encontrar una parte" ${ }^{\prime 4}$. También existe la posibilidad de que cada miembro de forma particular pueda instalar sus líneas captadoras de mitílidos entregando un porcentaje de las ganancias al sindicato.

\footnotetext{
${ }^{40}$ Entrevista con Don Juan Carlos Velásquez (El Manzano), realizada entre Marzo-Abril 2009.

${ }^{41}$ Idem
}

Puntilla Pichicolo: Para la pesca demersal se utilizan embarcaciones que no superan los $10 \mathrm{mt}$. de eslora, casi la totalidad de ellas son de madera, con motor fuera de borda o centrado. La especie objetivo es la Merluza, pero también explotan el congrio y la mantarraya. El tollo lo compran solo si pesa sobre $1 \frac{1}{2} 2$ kilos, la piel del tollo la compran en invierno aprovechando que en esa fecha abunda para elaborar harina de pescado. En cuanto a la carnada, son los intermediarios quienes se las proveen desde el sector de Hualaihué e Isla Los Toros, utilizando en promedio de 2 a 3 cajas al mes de sardina y pejerrey para la cuota de merluza. El arte de pesca usada para ésta pesquería es el espinel que van siendo reemplazados a medida que se deterioran por el uso o por perdida del material en faena, muchos de estos se hunden cuando el mar está muy picao ${ }^{42}$. El horario de zarpe es entre las 5 y las 6 de la mañana, cada embarcación sale con dos o tres tripulantes, el sistema de repartición de las ganancias es por partes.

\footnotetext{
${ }^{42}$ Expresión utilizada por los pescadores para referirse a un oleaje fuerte.
} 
Las zonas de pesca más concurridas son Ayacara, Poyo, Hueque, Golfo de Ancud, hay quienes en verano se trasladan hasta los canales de Llancahué (ver Cartografía n. 4). El desembarque y la comercialización de los productos se hace a través de intermediarios que vienen de la Isla Los Toros o Puerto Montt, ellos son los que se encargan de entregar los productos a las empresas en Puerto Montt. El precio de venta de la merluza varía entre los $\$ 800$ y $\$ 1.000^{43}$ el kilo.

La gran mayoría de los pescadores además de dedicarse a la pesca de la merluza, alternan la actividad con otro tipo de pesquerías, como la recolección de mariscos de orilla, el buceo y la captación de semillas de choritos mediante planteles de mitilicultura. La gran mayoría de ellos son oriundos de la caleta y han dedicado toda o gran parte de su vida a las labores del mar, cuentan con su Registro de Pescadores Artesanales ${ }^{44}$ al día, al igual que las embarcaciones.

La recolección de mariscos de orilla y el buceo se realiza una vez que se cierra la cuota de pesca para la merluza y lo practican tanto en las zonas libres como en las AMERB (ver Cartografía n. 5). Para quienes se dedican al buceo la especie objetivo es la cholga, para esta extracción no requieren reparar sus artes de pesca, a menos que pierdan los instrumentos (Palde, gualato); por su parte la recolección de orilla, se realiza en las orillas de la playa de Puntilla Pichicolo o bien tanto en las AMERB como en las zonas libres, en promedio sacan 30 mallas diarias que luego son vendidas en caleta Pichicolo Puerto a $\$ 2.200^{45} \mathrm{c} / \mathrm{u}$ a los compradores que vienen desde Concepción. Antes del auge por el cultivo y captación de semillas de choritos, la recolección una actividad rentable, sin embargo, hoy la oferta ha superado la demanda afectando directamente a los precios de comercialización de los productos.

Existe una visión generalizada respecto al futuro de la actividad pesquera en la caleta, coincidiendo en que la actividad ya no es rentable, y que se requiere seguir fomentando la captación y el cultivo de los choritos ya que ayudan a disminuir la sobreexplotación de la merluza.

El sindicato Puntilla Pichicolo tiene la administración de una Concesión Acuícola (ver Cartografía n. 5), sin embargo, los colectores son trabajados de forma independiente. Los colectores ${ }^{46}$ se ubican junto a la Isla Roca Huevo, lo mismo ocurre en el Sindicato Unión y Esfuerzo donde cada socio puede instalar sus colectores, contrario a lo que señala la Ley en ambos casos hay pescadores que admiten que sus colectores se encuentran por sobre o cercano a bancos naturales. Desde el año 2008 el Sindicato Unión y Esfuerzo tiene decretada una Concesión Acuícola de 33 hectáreas en la que pueden llegar a instalar 60.000 colectores, con el fin de capturar semillas y continuar con la etapa de engorda de los choritos.

Tal como señala el PLADECO ${ }^{47}$ de la Municipalidad de Hualaihué, efectivamente las aguas del sector son de muy alta calidad, esto lo han comprobado por la capacidad de captación que tienen los colectores, cada colector puede pesar hasta 15 kilos en semillas. La cosecha se realiza dos veces al año, la primera entre los meses de abril y mayo, y la segunda en septiembre, para lo cual se requieren entre 4 y seis personas. Para la etapa posterior a la captación, es decir, la engorda de las semillas se requiere más inversión en boyas para la flotación de los colectores.

\footnotetext{
${ }^{43}$ Dólar Observado a la Fecha \$ 480,22 http:/ / www. bolsadesantiago.com/web/bcs/home ( 9 de noviembre 2010) entre 1,6 y 2,08 dólares.

${ }^{44}$ Consiste en una nómina de pescadores y embarcaciones habilitadas para realizar actividades de pesca artesanal. Para los efectos de la Ley, éste se lleva por regiones, provincias, comunas y localidades, y por categorías de pescadores y pesquerías (SERNAPESCA http:/ / www.sernapesca.cl/index.php?option=com_co ntent\&task=view\&id=83\&Itemid=220)

${ }^{45}$ Dólar Observado a la Fecha \$ 480,22 http:/ / www. bolsadesantiago.com/web/bcs/home ( 9 de noviembre 2010) casi 5 dólares $(4,58)$ dólares.
}

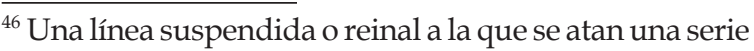
de cuelgas para la captación de semillas de choritos, esta estructura utiliza los fondeos de concretos para el anclaje de las líneas.

${ }^{47}$ Los Planes de Desarrollo Comunal PLADECOS son instrumentos de planificación y gestión con que cuentan los municipios para favorecer una administración eficiente de la comuna, promover iniciativas y proyectos destinados a la integración social, económica y territorial de los habitantes (MINISTERIO..., 2002).
} 


\section{Discusión y Conclusiones}

Los planteamientos de Marín (2007) son validados con el estado de las figuras de administración pesquera en las caletas estudiadas, en particular las Concesiones Acuícolas son restrictivas para los pescadores artesanales debido a la cantidad de trámites que se necesitan para su concesión, siendo difícil y a la vez caro el proceso de postulación y posterior administración. La segunda figura de administración pesquera citada en este estudio son las AMERB, pese a que fueron creadas con el propósito que fuesen administradas por organizaciones de pescadores artesanales, como una alternativa económica para este sector, fomentando la cohesión de los pescadores para que trabajen organizadamente tal como si fuese una empresa, se ve como en el caso de Caleta El Manzano, los sindicatos son utilizados como el medio legal para que las empresas puedan acceder a un beneficio exclusivo para los pescadores artesanales, los miembros del sindicato pasan a ser los representantes legales y la mano de obra. Las Concesiones Acuícolas también han sido objeto de mal uso, dado que la tramitación es lenta y engorrosa; resulta más fácil a los pescadores optar a permisos transitorios renovables de forma particular que permiten poner líneas de colectores de choritos dentro de la AMERB -que a su vez ha sido gestionada de manera colectiva- que tramitar un permiso incierto.

Desde los orígenes de las caletas sus pobladores han tenido sus propios sistemas de manejo, siendo primeramente recolectores de orilla, luego buzos mariscadores. Hoy la actividad de los recolectores de orilla se ve amenazada ya que cada vez son menos las zonas libres para poder pescar, todos los espacios tienen dueño, y los que no, están en proceso de llegar a tenerlo.

Aun cuando los datos no están actualizados al 2009, se puede apreciar la intensidad de uso del espacio marino, traslapándose zonas de pesca tradicionales con figuras de administración pesqueras, pocos espacios marinos sin dueño van quedando en la zona costera de las caletas.

Existe gran similitud entre las prácticas y usos del espacio marino para ambas caletas, en términos generales los pescadores reconocen los mismos hitos históricos, que han marcado la actividad pesquera en la zona, entre otros factores esto se puede atribuir a la proximidad territorial entre las caletas. Las especies objetivo explotadas son las mismas, es interesante notar como frente a la carencia de los recursos, en ambos lugares es de importancia el cuidado del medio ambiente, dado que con ello se resguarda el sustento del mañana, lo que en principio podía aparecer como mero discurso local, en muchos casos, se instituye como procesos y estructuras complejas a un nivel más global de la sociedad (SILVA, 2002).

La forma desmedida en que se explotaron los recursos pesquero-artesanales se debe, entre otras cosas, al cambio que han sufrido las prácticas pesqueras, que permitieron aumentar los volúmenes de captura de peces (especialmente la merluza) hasta finales de los ochenta, con cada vez más tecnologías. La rápida adopción y adaptación de las prácticas pesqueras es relatada por Berkes (2006) quien señala que cuando una nueva técnica de pesca es introducida, ese saber es reproducido rápidamente gracias a la habilidad que los pescadores tienen para aprender desde sus experiencia previas y al entendimiento que es fruto de la interacción permanente con el medio ambiente marino, esto permite que constantemente estén produciendo nuevos conocimientos retroalimentándose de la experiencia obtenida en el aprendizaje a partir del ensayo y error.

En el caso de la recolección de mariscos no se perciben grandes cambios entre ambas caletas. En las artes de pesca se siguen usando los mismos instrumentos de hace más de 50 años atrás, sólo ha cambiado la cantidad de personas que se dedican a esta actividad con fines comerciales y no únicamente para el consumo domestico; la razón: la introducción de nuevas formas de manejo de los recursos mediante el uso de técnicas de cultivo, más que de recolección.

En cuanto a la ocupación del espacio, las zonas de pesca históricas, son prácticamente las mismas, si bien en un principio no contaban con embarcaciones a motor para poder trasladarse a largas distancias por sus propios medios, los pescadores recuerdan haber sido remolcados hasta aquellas zonas más apartadas. Aun cuando los recursos objetivos han variado con el tiempo, las zonas 
siguen siendo las mismas. Sólo ha variado la frecuencia con la cual visitan estos lugares, hoy ya no es rentable salir tan lejos todos los meses para sacar como máximo 300 kilos; esta cantidad no alcanza a cubrir los gastos del viaje, esto no quiere decir que no frecuenten estas zonas, ya que en verano viajan hasta estos lugares más apartados a pescar, es en estos meses que aprovechan de pescar gran parte de la cuota total anual. Se desprende que la decisión sobre qué pescar, no ha dependido de una iniciativa personal, porque tal como paso con el tollo o la merluza, la explotación de estos recursos obedeció a la demanda de un particular que vio en el lugar una gran disponibilidad tanto de recursos como en mano de obra.

\section{Referencias}

BERAÚN, J. Transformaciones socio-territoriales en espacios con estructuras tradicionales 1992 - 2005. 2007. Tesis para optar a titulo Profesional de Geógrafo, Universidad Nacional Mayor de San Marcos, Lima, 2007.

BOLSA de Santiago. 2010. [En línea] <http://www. bolsadesantiago.com/web/bcs/home>. [Consulta: 9 de Noviembre 2010].

CANALES, M. Metodologías de investigación social: introducción a los oficios. Santiago: Lom Ediciones, 2006.

CÁRDENAS, R.; HALL, C. Chiloé: Manual del Pensamiento Mágico y la Creencia Popular. Castro: Ediciones Challanco, 2005. 104p.

CHAMBEAUX, J.; MICHEL, F.; RETAMALES, A. Escafandras bajo el mar, Origenes del buceo en las caletas de Carelmapu, Maullin y Quenuir. Santiago: Editorial Cuarto Propio, 2009. 141p.

EYLES, J. Los métodos cualitativos en geografía humana: bases teóricas y filosóficas y aplicaciones prácticas. En: GARCÍA, A. B. (Ed.). Métodos y técnicas cualitativas en geografía social. Tradução de P. Bosque. Barcelona: Oikos-tau, 1998. p. 33-44.

FREIRE, J.; GARCÍA-ALLUT, A. Integration of fishers ecological knowledge in fisheries biology and management. A proposal for the case of the artisanal coastal fisheries of Galicia (NW Spain), 1999. [Versión electrónica] Theme Session S. Evaluation of Complete Fisheries systems. Economic, Social, and Ecological Analyses. ICES.

FUNDACIÓN Chinquihue. Informe de Resultados Estudio de Situación Base (ESBA) y Propuesta Plan de Manejo de Isla Manzano, Región de Los Lagos. Chile: Fundación Chinquihue, 2008.

GARCÍA ALLUT, A.; FREIRE, J. Las cofradías, la comercialización y el cambio de paradigma. 2006. [En línea] <http://www.udc.es/dep/bave/jfreire/pdf_research/ Cofradias $\% 20 y \% 20$ comercializacion $\% 20 \% 28 W P \% 20$ v1\%20FEB06\%29.pdf> [Consulta: 10 de Noviembre 2010].
GRANT, S.; BERKES, F. Fisher knowledge as expert system: A case from the longline fishery of Grenada, the Eastern Caribbean. Fisheries Research, n. 80, p. 162170, 2007.

GUALARTE, A.; GIRONDO, E. Artisanal fishing areas and traditional ecological knowledge: The case study of the artisanal fisheries of the Patos Lagoon estuary (Brazil). Marine Policy, v.32, p. 283-292, 2008.

GUDIÑO, M. Transformaciones territoriales asociadas a la globalización, una reflexión teórica-metodológica. Tiempo y Espacio, Chillan, Chile, n. 15, 2005.

ILUSTRE MUNICIPALIDAD DE HUALAIHUÉ. PLADECO Comuna de Hualaihué 2007-2012. Hualaihué, Chile, 2009.

INSTITUTO DE SALUD PÚBLICA DE CHILE (s/f) [En línea] <http://www.ispch.cl/encabezado/funcion/ resena.html>. [Consulta: 16 de Noviembre 2010]

KLEIN, J. Geografía y desarrollo local. En: LINDÓN, A.; HIERNAUX, D. Tratado de geografía humana. Barcelona: [s.n.]: 2006. p. 303-319.

LEY General de Pesca y Acuicultura, Ley n. 18.892, de 1989 y sus modificaciones, actualizada en octubre de 2008.

MARÍN, W. Cultura y modernización de la pesca artesanal en Chile: adaptaciones, cambios e hibridaciones en una caleta de algueros. Revista Mad., n. 17, p. 113143, 2007.

MARTÍNEZ, A.; LATORRE, E. Revisión taxonómica del género Virilastacus Hobbs, 1991 (Crustacea, Decapoda, Parastacidae). En Exposiciones Póster Lunes 16 de mayo Crustáceos XXV Congreso de Ciencias del Mar, Escuela de Ciencias del Mar Pontificia Universidad Católica de Valparaíso, Viña del Mar, mayo 2005.

MÉNDEZ, R. La construcción de redes locales y los procesos de innovación como estrategias de desarrollo rural. Problemas del Desarrollo Revista Latinoamericana de Economía, v. 37, n. 147, p. 217-240, 2006.

MURILLO, O. Análisis del discurso social. Investigaciones Sociales, año VIII, n. 13, p. 369-385, 2004.

NAYLOR, R.; BURKE, M. Aquaculture and Ocean Resources: Raising Tigers of the Sea. Annual Review of Environment \& Resources, v. 30, p. 185-218, 2005.

PEÑA, J.; BUSTOS, R.; PÉREZ, C. Mercados Informales y Control Vertical: Comercialización de Pesca Artesanal Perecible. 2005. [En línea] <http:/ / economia.uahurtado. $\mathrm{cl} / \mathrm{pdf} /$ publicaciones/inv161.pdf $>$. [Consulta: $21 \mathrm{de}$ Noviembre 2010].

PONTIFICIA UNIVERSIDAD CATÓLICA DE CHILE. Bases técnicas para el plan de manejo de la pesquería demersal austral, 2009.

REYES, E. ¿Qué pasó con el loco? Crónico de un colapso anunciado. 1986. [En línea] <http://200.75.6.169/ RAD/1986/2_Reyes.pdf > [Consulta: 21 de Noviembre 2010].

ROGEL, M. Pescadores y Estado: la pertinencia cultural de los proyectos de desarrollo para los pescadores de Chile, el caso de los pescadores artesanales de la comuna de Hualaihué décima región de Los Lagos. Tesis para 
optar al título profesional de Antropólogo y al grado académico de Licenciado en Antropología, Universidad Austral de Chile, Valdivia, 2006.

ROSALES, R. Geografía Económica. En: LINDÓN, A.; HIERNAUX, D. Tratado de geografía humana. Barcelona: [s.n.], 2006. p. 71-83.

RUIZ, A.; MADRID, J. Análisis comparativo de tres sistemas de pesca artesanal. Región y Sociedad, v. VIII, n. 13-14, 1997.

SALINAS, P. Transcripción. Encuesta Bioeconómica de pesca artesanal, Abril-Mayo 2009.

SANTANA, R. ¿Cómo se investiga en ciencias sociales? Una repuesta a "vuelo de pájaro". En: Diálogos Académicos del CEDER (Ed.). Niveles y perspectivas de investigación en ciencias sociales diseños investigativos, Osorno, 2003. p. 27-36.

SECRETARÍA REGIONAL DE PLANIFICACIÓN Y COORDINACIÓN REGIÓN DE LOS LAGOS. Estrategia de Desarrollo Regional - Los Lagos, 2000-2010. Puerto Montt: Gobierno Regional de Los Lagos, Chile, 2000.

SERVICIO NACIONAL DE PESCA (SERNAPESCA). Pesca Artesanal [En línea] <http:/ / www.sernapesca. $\mathrm{cl} /$ index.php?option $=$ com_content\&task $=$ view\&id= 83\&Itemid=220>. [Consulta: 23 de Noviembre 2010]
Gob. de Chile. Análisis de inversión de fomento productivo para la pesca artesanal, 1999-2003. Chile: Departamento de Pesca Artesanal / Servicio Nacional de Pesca, 2004

SILVA, O. Análisis del discurso según Van Dijk y los estudios de la comunicación. CEM. Abril - Mayo 2002. Disponible en: <http://www.cem.itesm.mx/dacs/ publicaciones/logos/anteriores/n26/osilva.html>.

SOMS GARCÍA, Esteban. Ministerio de Planificación y Cooperación. Metodología para la elaboración de Planes de desarrollo comunal, [libros]. Chile, Santiago, [s.n.], 2002. 106p.

SUBSECRETARIA DE PESCA (SUBPESCA). Política Nacional Pesquera 2007. [En línea] <http:/ / www.subpesca. $\mathrm{cl} /$ template $/ 0$ foto $/ 05$.asp?idseccion $=2198>$ [Consulta: 15 de Agosto de 2009]

THER, F. Las sociedades litorales como sistema de prácticas y saberes tradicionales y científicos: la caleta como modelo de imaginarios pesqueros dinámicas de uso y apropiación de recursos marinos (Proyecto FONDECYT 1080665) Región de los Lagos: Centro de Estudios del desarrollo Local y Regional \& Depto. Ciencias básicas, laboratorio de genética y Acuicultura, Universidad de Los Lagos, 2008.

ZULETA, A. ¿Cómo Expandir los Límites? Revista ambiente y desarrollo, v. VI, n. 3, 1990. 
